\title{
Work on 'non-lethal' weapons should be limited too
}

\author{
Security fears have led to violation of international law before. It must not happen again.
}

Sir - Given the prevailing threat of terrorist use of biological weapons, I welcome the statement by journal editors and authors (Nature 421, 771; 2003) affirming their responsibility to censor work that could compromise biodefence and biosecurity. This measure may help avert misapplication of research findings.

However, the threat posed by 'nonlethal' weapons research, the results of which are not usually submitted for publication, also warrants attention. These include unpublished research into weapons such as 'calmative gases' and biologically engineered anti-material bacteria.

Given the casualties they can claim (see Nature 420, 7; 2002), the term 'non-lethal' weapons is a misnomer. Research on such weapons might violate international chemical and biological anti-proliferation treaties. Just as journals and authors are taking a stand against publishing potentially dangerous research findings, so too should the world's scientists actively condemn proactive research into these kinds of weapons.

The South African experience has

shown how an acquiescent attitude towards weapons research that violates international law, on the grounds of patriotism and security fears, can compromise the legal and ethical responsibilities of people and research institutions. From 1983 to 1993 , under the auspices of Project Coast — the apartheid government's covert chemical and biological weapons programme - South African scientists, physicians and academic experts put their expertise into developing secret and novel weapons (see Nature 393, $724 ; 1998)$. In so doing, they unleashed agents and weaponry that violated South Africa's international-law obligations.

History now questions the ethics of the scientists who contributed to this programme, and of the institutions to which they belonged. History will judge today's scientists and institutions similarly should they turn from their ethical and legal obligations in the face of security pressures.

I do not suggest that scientists should totally refrain from involvement in weapons research. But, for the sake of world security, scientists in all disciplines that could conceivably be involved in novel 'non-lethal' weapons development should learn from the South African experience.

They must commit themselves to knowing, respecting and adhering to the legal instruments that govern chemical and biological warfare. They must commit themselves to drafting a scientific moral code based on benevolent ethical principles. They must lobby their governments to adhere to anti-proliferation laws and declarations, and to ratify verification protocols associated with these declarations. They must report infringements of these laws to the relevant authorities. Most importantly, they must ensure that a Pandora's box of deadly 'non-lethal' weapons never gets built, let alone opened. Jerome Amir Singh

Howard College School of Law, University of Natal, Durban 4041, South Africa, and University of

Toronto Joint Centre for Bioethics, 88 College Street, Toronto M5G 1L4, Canada

\section{Universities could gain from backing biotech}

Sir - Since the inception of the biotechnology industry more than two decades ago, the major pharmaceutical companies have supported discovery-phase research in the sector through collaborations and out-sourcing. Even when the economics seemed unfavourable to the biotechnology company, these arrangements have been beneficial in critical ways.

But the earliest phases of $\mathrm{R} \& \mathrm{D}$ - target discovery, validation and screening — are receiving less and less support within the pharmaceutical industry. The major companies are under enormous pressure to continue high growth, while dealing with unspectacular results of genomics collaborations, consolidation and the establishment of internal infrastructure. All this has greatly reduced their appetite for discovery-phase partnerships with biotech start-ups.

A preference for late-stage product opportunities will create long-term problems for the drug industry and for health care in general. Clinical compounds do not materialize out of thin air. If the pipeline input is squelched, the downstream output will eventually tail off.

The change in the commercial funding environment creates some interesting opportunities for academic institutions. Without departing from their primary mission of assisting the public good through education and other services, they could seize the chance to fill this gap and attract government funds for discovery-stage work. As projects mature, universities could create mechanisms to transfer programmes into a commercial setting where they can exploit greater amounts of private capital and command higher returns on investment than has typically accrued to them.

Universities can already tap into large sums of public money to support work of medical value. If they could undertake a focused effort on early-stage technology and drug-discovery R\&D, I believe that a relatively simple and productive transfer into the private sector could be arranged. The universities could find the business expertise necessary to launch companies successfully through their internal resources and through cultivated venturecapital groups. Academic institutions could thus exert considerable control over commercialization of their discoveries.

A properly conceived and managed university unit of this type would require an initial investment of funds before becoming self-sufficient. Once the infrastructure is built, a unit could rapidly become a source of income for the university through government grants, research contracts and, ultimately, its own commercial ventures.

Returns on the initial investment would probably derive in part from royalties on exclusive (for example, drug) or non-exclusive (for example, technology) licences. In addition, universities could gain income through equity positions in companies that they help to found, and institute regulations to ensure openness and mitigate perceptions of conflict and exploitation.

Universities stand to benefit in several other ways. Much of the infrastructure for target validation and drug screening operations could be used to accelerate, and possibly transform, their own applied or basic research activities. These services could be provided by the unit as a core facility or as collaborative projects. For instance, a target validation or chemical screening system could be used by any faculty member wishing to explore the roles of his or her favourite genes in a specific disease area.

Alexander Kamb

Deltagen Proteomics, 615 Arapeen Drive, Salt Lake City, Utah 84108, USA

\section{correspondence}

Contributions to Correspondence may be submitted to corres@nature.com. They should be no longer than 500 words, and ideally shorter. Published contributions are edited. 